La inseguridad y los medios de comunicación en su laberinto: una mirada desde América Latina

Violeta Dikenstein

Question, Vol. 1, N. 57, e032, enero-marzo 2018. ISSN 1669-6581

http://perio.unlp.edu.ar/ojs/index.php/question/article/view/4370

FPyCS | Universidad Nacional de La Plata

La Plata | Buenos Aires | Argentina

Recibido: 21-09-2017 Aceptado: 19-10-2017

Cita sugerida: Dikenstein, V. (2018). La inseguridad y los medios de comunicación en su laberinto: una mirada desde

América Latina. Question, 1(57), e032. doi: https://doi.org/10.24215/16696581e032

\title{
La inseguridad y los medios de comunicación en su laberinto: una mirada desde América Latina
}

\author{
Insecurity and the media in its labyrinth: a look from Latin America
}

Violeta Dikenstein

Instituto de Altos Estudios Sociales; Universidad Nacional de San Martín/ Consejo Nacional de Investigaciones Científicas y Técnicas (Argentina) violeta.dik@gmail.com

\section{Resumen}

El siguiente trabajo consiste en una reseña de la compilación recientemente publicada por Brenda Focás y Omar Rincón, titulado (In)seguridad, medios y miedos: una mirada desde las experiencias y las prácticas cotidianas en América Latina. Se realiza un recorrido por los diversos artículos que componen el libro de acuerdo a dos ejes analíticos: los trabajos que reparan en las construcciones mediáticas sobre el delito, y aquellos que abordan la recepción y el rol de las noticias criminales en la configuración de percepciones de inseguridad. La reseña concluye con una reflexión acerca de los aportes y futuras pistas de indagación que habilita la obra. 
Palabras clave: inseguridad; medios de comunicación; percepciones; temor al delito.

\section{Abstract}

The following work is a review about the recently published compilation by Brenda Focás and Omar Rincón, entitled (In)seguridad, medios y miedos: una mirada desde las experiencias y las prácticas cotidianas en América Latina. The description and analysis of the articles that compose the book is carried out according to two analytical axes: the works that focus on the media constructions about crime, and those that consider the reception and the role of criminal news in the configuration of perceptions of insecurity. The review concludes with a reflection on the contributions and future clues of inquiry that enables the work.

Keywords: insecurity; media; perceptions; fear of crime.

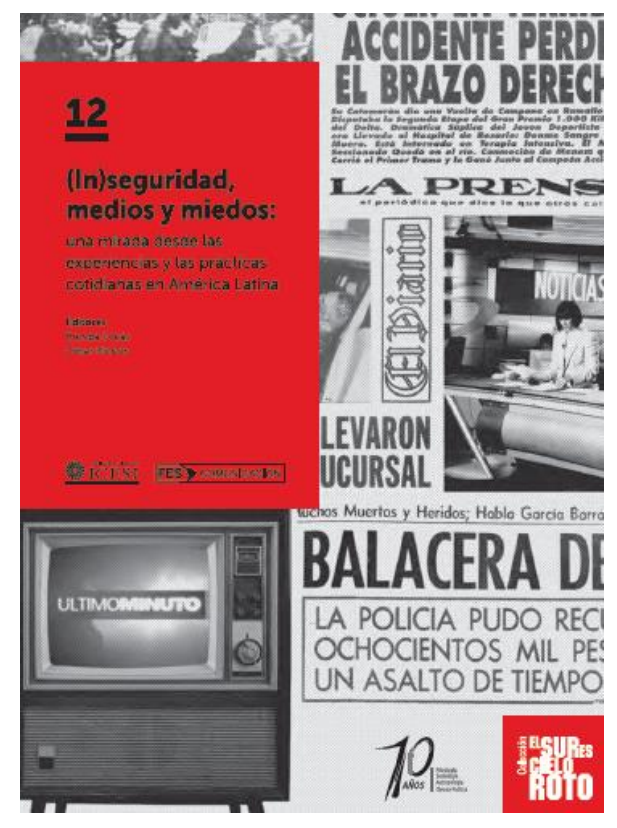

Título: (In)seguridad, medios y miedos: una mirada desde las experiencias y las prácticas cotidianas en América Latina

Editores: Brenda Focás y Omar Rincón

Año: 2017

Colección: El sur es cielo roto

Ediciones: ICESI + FEScomunicación

ISBN: 978-958-8936-19-2

Número de páginas: 328

En los últimos años, el interrogante en torno al temor al delito y su vinculación con los medios de comunicación ha dado lugar a un nutrido debate en nuestra región. El ascenso de la problemática como foco de preocupación en las encuestas de opinión pública, así como su 
cobertura cada vez más amplia en los medios, redundó en un creciente interés por parte de las ciencias sociales latinoamericanas.

Pionera en estos estudios, la producción académica de la línea anglosajona fue tan vasta que una serie de autores se dedicaron a recopilarla y clasificarla (1). Con una intención similar, y desde nuestro continente, (In)seguridad, medios y miedos: una mirada desde las experiencias y las prácticas cotidianas en América Latina, reúne artículos sobre la temática.

Sin embargo, mientras que los estudios anglosajones se caracterizan por un abordaje más bien homogéneo y sistemático, basado en el predominio de la estrategia metodológica cuantitativa, (In)seguridad, medios y miedos pone de manifiesto la heterogeneidad en estilos de trabajo, metodologías y técnicas de indagación, así como la especificidad que adopta la problemática en el contexto latinoamericano. El resultado es una obra polifónica donde se reúne un conjunto de investigaciones que indagan a un mismo objeto. Esta característica deviene en polisemia cuando se trata el problema en los diversos países: en efecto, la inseguridad no adopta el mismo significado en México, El Salvador o en Chile, por citar algunos ejemplos.

En la introducción se formula el interrogante que atraviesa el libro: ¿qué lugar ocupan los medios en la configuración de las percepciones en torno al temor y la inseguridad? A lo largo de la obra se hará visible que la problemática no resiste explicaciones simplistas y unilaterales, sino que abre un plexo de paradojas, tensiones y matices que exigen agudeza en el análisis.

El texto admite lecturas cruzadas, ordenamientos y reordenamientos según ejes analíticos diversos. Una de las líneas posibles consiste en distinguir los trabajos que reparan en las construcciones mediáticas sobre el delito y la inseguridad. Tal como anticipa el periodista Cristian Alarcón en la entrevista que prologa la obra, los relatos mediáticos sobre la delincuencia y la violencia han funcionado en América Latina como velo para soslayar las grandes desigualdades que signan al continente. En ese sentido, Suzana Varjão indaga los programas policíacos en Brasil y su uso de narrativas unidireccionales, carentes de diversidad de fuentes y proclives a legitimar la violencia estatal a los jóvenes pobres. Jaris Mujica, Sofía Vizcarra y Nicolás Zevallos analizan las primeras planas del periódico peruano El Comercio, tendiente a sobrerrepresentar los crímenes violentos (estadísticamente menores en comparación con otros tipos de delitos). Por su parte, Luis Fernando Barón Porras retoma trabajos académicos que abordaron la relación entre medios, conflicto armado, inseguridad y temor en Colombia.

Dentro de un segundo gran eje, encontramos aquellos trabajos que optan por adentrarse en el sinuoso terreno de la recepción y del rol de las noticias criminales en la configuración de percepciones de inseguridad. Se aprecia aquí una rica variedad de abordajes metodológicos, casos y fuentes. Luanda Dias Schramm desarrolla una etnografía de audiencias en un grupo de jóvenes brasileños, en torno al caso del asesinato del "Indio Galdino" (de la etnia Pataxó, asesinado por cinco jóvenes de clase alta en Brasilia). El artículo permite apreciar los modos 
en que la recepción del texto televisivo es un proceso activo, donde intervienen múltiples mediaciones. En el escenario argentino, Brenda Focás indaga mediante un estudio cualitativo las percepciones de inseguridad que se conforman a partir del consumo de contenidos mediáticos. Observa que los entrevistados son portadores de una mirada crítica y cuestionadora de los medios: los reconocen como empresas con intereses propios y como constructores de las noticias. En un trabajo cualitativo de corte etnográfico, Célia Regina Polesel analiza las decodificaciones del programa policial y sensacionalista Tempo Quente, en el seno de una familia residente de un barrio popular brasilero reconocido por la violencia. En sintonía con los trabajos recién reseñados, destaca el carácter negociado del sentido de los mensajes televisivos. Por su parte, Magdalena Browne Mönckeberg y Sebastián Valenzuela se interrogan acerca de la incidencia del consumo de televisión en la opinión pública sobre la delincuencia. Por medio de un estudio cuantitativo observan que, en el caso de las audiencias chilenas, la exposición a los medios de comunicación no opera como única determinante en las opiniones sobre el tema, sino que emerge como un factor más que actúa de modo heterogéneo según la posición política, el nivel socioeconómico, el género y la experiencia de victimización de los actores.

Al interior de la compilación, hay textos que tensionan al máximo la discusión. El trabajo de Celia del Palacio Montiel en Veracruz, México, es uno de ellos. En un contexto signado por cifras alarmantes de secuestros y desapariciones forzadas, asesinatos a periodistas, ataques a los medios y la consecuente reducción de notas en las secciones policíacas; el debate en torno a la incidencia de los medios en las representaciones del temor se ve fuertemente trastocado. Es así como la problemática se invierte: la pregunta no es por el efecto de que puede conllevar una sobrerrepresentación de noticias de delito y violencia, sino su silenciamiento. En esta trama, se pone en evidencia una vez más de qué manera la recepción no es un proceso acrítico: los entrevistados coinciden en que los medios de comunicación no muestran la situación real de violencia que se vive en ese territorio.

En El Salvador, Amparo Marroquín Parducci presenta otro escenario complejo: ante un crecimiento exponencial de la tasa de homicidios, los poderes políticos responsabilizan a los medios de comunicación de las altas percepciones de temor en los ciudadanos. En este contexto, a través de un análisis de las audiencias de dos medios de características muy diferentes, la autora analiza las narrativas sobre la violencia de las pandillas, las reacciones frente al tema y la diversidad de respuestas que producen.

Los medios de comunicación son cruciales cuando determinados colectivos de víctimas se agrupan y pugnan por un espacio de visibilidad. En este sentido, Santiago Galar analiza las prácticas sostenidas en el espacio público por parte del activismo en torno a la inseguridad, la búsqueda por obtener un tratamiento mediático de sus demandas y los aprendizajes que esto entraña por parte de los actores. 
El libro finaliza con un epílogo de Omar Rincón donde, con un gran vuelo ensayístico, reflexiona sobre la fuerza performativa del miedo en tanto constructor de ciudadanías individualistas y súbditas; así como su efecto restrictivo de los espacios públicos y la particular atracción que produce en los medios de comunicación.

(In)seguridad, medios y miedos... es, sin duda, un aporte valioso por varios motivos. El más evidente, porque tiene la virtud de hacer confluir interrogantes comunes hasta entonces dispersos en las ciencias sociales latinoamericanas. Asimismo, permite escapar a lecturas simplistas en torno a los medios como meros productores de temor, así como de las audiencias como consumidoras acríticas. En la secuencia de artículos que componen el libro se puede apreciar la complejidad de realidades bajo las que se encuadran estos conceptos, lo cual abre la posibilidad de continuar profundizando estos interrogantes que signan a la región y acompañan nuestra experiencia contemporánea.

\section{Notas}

(1) Ver Hale, 1996; Farral, Sacco y Grey, 2007, entre otros.

\section{Bibliografía}

Focás, B. y Rincón, O. (editores). (2016). (In)seguridad, medios y miedos: una mirada desde las experiencias y las prácticas cotidianas en América Latina. Bogotá: Ediciones ICESI y FES comunicación.

Farrall, S.; Jackson, J. y Gray, E. (2007). Theorising the Fear of Crime: The Cultural and Social Significance of Insecurities about Crime. Experience \& Expression in the Fear of Crime Working Paper, 5.

Hale, Ch. (1996). Fear of crime: a review of the literature. International Revieu of Victimology, $4(2)$. 